\title{
Estudo de Caso do Programa de Educação Ambiental Fruto da Terra: a pedagogia de projetos como estratégia para a educação ambiental crítica
}

\author{
Sheila $\operatorname{Ceccon}^{1}$ \\ Maurício Compiani ${ }^{2}$ \\ João Luiz de Moraes Hoeffel ${ }^{3}$
}

Resumo: A pesquisa aqui relatada é um estudo de caso do Programa de Educação Ambiental Fruto da Terra, tendo como foco a pedagogia de projetos e a construção da educação ambiental crítica. Foram analisadas estratégias de formação de professores e de ensino-aprendizagem desenvolvidas pelo programa junto a 17 escolas, do $1^{\circ}$ ao $5^{\circ}$ ano do ensino fundamental da rede pública municipal de Atibaia - SP, no período de 2003 a 2008. Como estratégias de formação de professores, foram realizados cursos, Encontros Municipais de Educação Ambiental, reuniões mensais de estudo e formação junto aos coordenadores pedagógicos das 17 escolas envolvidas e estudos periódicos realizados por esses coordenadores junto às suas equipes de professores, em Horários de Trabalho Pedagógico Coletivo (HTPCs). Como método de ensino-aprendizagem e instrumento de educação ambiental crítica, a opção do programa foi pela pedagogia de projetos. No período estudado, é possível perceber transformação do fazer educativo de muitos educadores e a realização de práticas pedagógicas contextualizadas e não disciplinares, contribuindo para a formação de sujeitos participativos.

Palavras-chave: educação ambiental crítica, pedagogia de projetos, formação de professores.

Abstract: The research reported here is a case study of the Environmental Education Program - Fruits of the Earth, whose main focuses are the pedagogy of projects and the construction of a critical environmental education process. Strategies for the teacher training and teaching-learning processes developed by the Program were analyzed in 17 schools, from $1^{\text {st }}$ to $5^{\text {th }}$ year of

1 Coordenadora do Programa de Educação Ambiental Fruto da Terra na Secretaria de Educação da Prefeitura de Atibaia - SP, mestranda do Programa de PósGraduação em Ensino e História de Ciências da Terra do Instituto de Geociências / UNICAMP. Contatos: R. Rio Preto, 671, Jd.Paulista - Atibaia - SP. CEP 12947410 ou sheilaceccon@yahoo.com.br

2 Coordenador do Programa de Pós-Graduação em Ensino e História de Ciências da Terra do Instituto de Geociências / UNICAMP. compiani@ige.unicamp.br

3 Professor e Pesquisador na Universidade São Francisco, Bragança Paulista, onde coordena o Centro de Estudos Ambientais - Sociedades e Naturezas. jlhoeffel@yahoo.com.br 
basic education in public schools of Atibaia - SP, from 2003 to 2008. Such strategies included teacher training courses, Municipal Environmental Education Meetings, monthly study meetings and training with educational coordinators from the 17 schools involved, and regular studies carried out by these coordinators with their teachers' team, in periods of Collective Pedagogical Work (HTPC). As a method of teaching-learning process and an instrument of critical environmental education, the program option was the pedagogy of projects. The period analyzed showed transformation of the educational process developed by many educators and implementation of contextualized and non-disciplinary educational practices, thus contributing to the development of participatory agents.

Keywords: critical environmental education, pedagogy of projects, teacher training.

\section{Introdução}

Este artigo discute a educação ambiental no ensino formal, nos anos iniciais do Ensino Fundamental, tendo como referência o processo desenvolvido de 2003 a 2008 na rede pública municipal de Atibaia - SP. A partir do estabelecimento de parceria entre uma ONG local e a Secretaria Municipal de Educação de Atibaia em junho de 2001, foram realizados encontros mensais entre onze técnicos em educação oriundos das duas entidades durante um período de dezoito meses, resultando na elaboração e implantação do Programa de Educação Ambiental Fruto da Terra, em toda a rede pública municipal de educação, a partir de fevereiro de 2003. Em março de 2008, o programa tornou-se Política Pública Municipal ao ser incluído no Plano Municipal de Educação e aprovado por setenta delegados na Conferência Municipal de Educação da cidade.

Neste artigo, nossa reflexão está dirigida a educadores e alunos de $1^{\mathrm{a}}$ a $4^{\mathrm{a}}$ série nos anos de 2003 a 2006 , e do $1^{\circ}$ ao $5^{\circ}$ ano em 2007 e 2008, quando crianças de seis anos passaram a fazer parte do Ensino Fundamental. Em 2008, a rede pública municipal de Atibaia possuía 220 educadores e 7.369 crianças que cursavam os anos iniciais do Ensino Fundamental, em 17 escolas da cidade.

Ao longo dos seis anos estudados, foram desenvolvidas metodologias de formação de professores e de ensino tendo como foco a pedagogia de projetos como estratégia para o desenvolvimento da 
educação ambiental crítica. O propósito desta pesquisa é analisar o processo desenvolvido à luz de referenciais teóricos da educação ambiental crítica, buscando identificar contribuições e limitações do método adotado.

Este estudo foi desenvolvido a partir da perspectiva da coordenadora de todo o processo, pesquisadora que esteve à frente do programa desde o período de elaboração do mesmo até sua efetivação como política pública.

\section{Metodologia da pesquisa}

A metodologia adotada para esta pesquisa é o estudo de caso, pesquisa empírica considerada adequada para a investigação de um fenômeno contemporâneo dentro de seu contexto real.

A essência do estudo de caso é a tentativa de esclarecer uma decisão ou um conjunto de decisões: por que foram tomadas, como foram implementadas e quais os resultados alcançados (YIN, 2003). Como estratégia de pesquisa, caracteriza-se pelo interesse em casos individuais e não pelos métodos de investigação, os quais podem ser os mais variados, tanto qualitativos como quantitativos (STAKE, 2000, apud ALVES-MAZZOTTI, 2004). Neste estudo, a opção foi pela análise qualitativa do processo desenvolvido.

Pesquisa qualitativa é compreendida aqui como um conjunto de diferentes técnicas interpretativas que visam a descrever e a decodificar os componentes de um sistema complexo de significados. Ela tem por objetivo traduzir e expressar o sentido dos fenômenos do mundo social, buscando reduzir a distância entre indicador e indicado, teoria e dados, contexto e ação (MAANEM, 1979, apud NEVES, 1996).

O estudo de caso do Programa de Educação Ambiental Fruto da Terra foi desenvolvido com a realização de três atividades de naturezas diferentes: (1) levantamento de referenciais teóricos; (2) pesquisa documental; (3) identificação de contribuições e limitações do método adotado, tendo como foco a educação ambiental crítica. 
1. O levantamento de referenciais teóricos envolveu o resgate de textos de diferentes autores, que foram estudados pelo grupo de 2003 a 2008, e a análise da relação existente entre as práticas adotadas nas escolas a partir do desenvolvimento do programa e os fundamentos da educação ambiental crítica.

Educação ambiental crítica é compreendida aqui como aquela que busca promover ambientes educativos de mobilização de processos de intervenção sobre a realidade e seus problemas socioambientais; trabalha na perspectiva da construção do conhecimento contextualizado para além da mera transmissão de informações e promove a percepção de que o processo educativo não se restringe ao aprendizado individualizado dos conteúdos escolares, dando-se na relação do um com o outro, do um com o mundo (GUIMARÃES, 2004). A educação ambiental crítica motiva a ação, contribui para o rompimento do imobilismo provocado pelo ensino descontextualizado. É uma educação política na medida em que provoca a intervenção na realidade a partir do conhecimento adquirido.

2. A pesquisa documental envolveu a análise dos seguintes registros produzidos ao longo dos seis anos estudados: avaliações elaboradas voluntariamente por educadores após a realização de oito grandes Encontros e seis Exposições Municipais de Educação Ambiental; avaliações individuais elaboradas após a realização dos cursos "Pedagogia de Projetos" e "Educação Ambiental e Interdisciplinaridade"; conteúdos abordados nos principais cursos, oficinas e vivências oferecidos aos educadores e conteúdos trabalhados pelos coordenadores junto às suas equipes de professores em Horários de Trabalho Pedagógico Coletivo (HTPCs). Foram analisados ainda depoimentos de coordenadoras pedagógicas, levantadas concepções de educação ambiental existentes antes e depois do desenvolvimento do programa e resgatados registros de projetos de educação ambiental desenvolvidos com base no processo de formação realizado. 
Considerando a concepção de educação ambiental crítica adotada, optou-se pela análise das práticas de educação ambiental desenvolvidas nas escolas da seguinte perspectiva:

a. Houve criação de condições de interferência concreta das crianças no meio?

b. Existiu contextualização?

c. O enfoque do trabalho foi disciplinar ou não?

d. Houve motivação para a confrontação de hipóteses, para o trabalho em equipe e para atitudes solidárias e éticas?

3. Identificação de contribuições e limitações da metodologia adotada, tendo como foco a educação ambiental crítica.

Segundo Loureiro (2005, apud FERRARO JÚNIOR, 2005), o principal indicador de sucesso de uma ação educativa ambiental crítica não está em alcançar metas previamente definidas, mas em estabelecer um processo de aprendizagem que seja participativo, emancipatório e transformador. É com esse enfoque que o programa em estudo foi analisado na etapa final deste trabalho. O processo descrito nos itens anteriores subsidiou então uma reflexão sobre a pedagogia de projetos como instrumento de educação ambiental crítica, no contexto estudado.

O presente artigo traz um breve diagnóstico da rede pública municipal de Atibaia no período anterior à realização do Programa Fruto da Terra, analisa a metodologia de formação de professores e de ensino desenvolvidas e, para finalizar, discorre sobre potenciais contribuições e limitações da metodologia adotada.

\section{Diagnóstico para a elaboração do Programa}

As ações realizadas foram planejadas a partir de um diagnóstico construído através da relação direta com diretoras das dezessete escolas envolvidas, coordenadoras pedagógicas de cada uma delas e educadores presentes em diferentes grupos de estudo e de formação. Foi constatado que, apesar de os profissionais compreenderem como importante e pertinente o que consta nos Parâmetros Curriculares 
Nacionais como objetivos do Ensino Fundamental, havia uma grande distância entre o que é preconizado pelo MEC e o que era vivenciado pelas crianças.

Segundo os PCN, são objetivos do Ensino Fundamental, entre outros, desenvolver uma prática pedagógica que leve o aluno a perceber-se integrante, dependente e agente transformador do ambiente, identificando seus elementos $\mathrm{e}$ as interações destes e contribuindo ativamente para a melhoria do meio ambiente, e, ainda, que o leve a questionar a realidade formulando problemas e tratando de resolvê-los, utilizando para isso o pensamento lógico, a criatividade, a intuição, a capacidade de análise crítica, selecionando procedimentos e verificando sua adequação.

Entretanto, apesar de todos serem professores polivalentes, ou seja, responsabilizarem-se pelo ensino de todas as áreas de conhecimento, o conteúdo era abordado com forte enfoque disciplinar: uma área de conhecimento não dialogava com a outra, e o conhecimento abordado não estabelecia necessariamente relação com o mundo real vivido pelas crianças. O conhecimento não era colocado a serviço da compreensão do mundo, mas, em sentido oposto, situações e fenômenos da realidade eram citados para exemplificar o tema abordado. O foco era sempre o conteúdo do livro didático, na sequência por ele imposta, e não o contexto vivido pelas crianças e a gama de saberes que permeia esse território. Por outro lado, práticas educativas criativas e produtoras de ótimos resultados, quando desenvolvidas por profissionais da rede, permaneciam restritas à equipe da escola ou, não raro, nem com a própria equipe eram compartilhadas. Os profissionais rejeitavam a ideia de divulgar práticas pedagógicas de sua autoria, com uma forte tendência de evitar críticas de colegas.

Assim, a educação ambiental era compreendida como a relação do ser humano com plantas e animais e com o meio físico. As relações humanas estavam de forma geral excluídas desse contexto. Ao mesmo tempo, havia grande desconhecimento dos educadores em relação à própria cidade: de onde vem a água que é consumida, para onde vai quando sai da escola ou das casas, para onde vai o lixo e o esgoto produzidos, quanto lixo é produzido, etc. 
As escolas não haviam construído seus Projetos Políticopedagógicos, não havia preocupação em pensar qual a função social da escola e como a escola precisa agir para cumpri-la. Não havia o hábito de registrar o processo pedagógico desenvolvido e a história permanecia quase exclusivamente na memória dos profissionais e alunos envolvidos.

O cenário educativo encontrado estava em sintonia com o apontado por Compiani (2005): as aulas tradicionais e o livro didático predominantes nas escolas eram descontextualizados e centrados no enciclopedismo das definições. Ensinavam-se repertórios e definições, informações, de modo geral, trabalhadas por educadores de maneira isolada e fragmentada, refletindo a organização das informações divididas nas unidades e subunidades dos livros didáticos. A escola, de certo modo, ignorava a vida, pois idealizava um aluno abstrato, sem tempo e sem espaço. O aluno real, em seu contexto, com sua experiência social e individual em sua localidade, era ignorado. Por não ter um interlocutor real, a escola era incapaz de ocupar seu lugar de produtora de conhecimentos gerados na interação do mundo cotidiano com o científico.

\section{Metodologia da formação de professores}

Como metodologia de formação de professores, foram realizadas quatro ações principais: (1) o oferecimento de cursos, oficinas, vivências e palestras como estratégia de formação continuada de educadores; (2) a utilização dos Horários de Trabalho Pedagógico Coletivo (HTPCs) para estudo das equipes docentes; (3) a realização de um registro reflexivo de todo o caminhar do programa e o incentivo à produção de registros por parte dos professores e (4) uma ampla socialização das experiências de sucesso resultantes de todo o processo.

De 2003 a 2008, 150 educadores do ensino fundamental realizaram o curso "Pedagogia de Projetos como Instrumento de Educação Ambiental”. Em 2007 e 2008, 80 educadores realizaram o curso "Educação Ambiental e Interdisciplinaridade".

O objetivo maior do curso Pedagogia de Projetos foi sensibilizar o grupo quanto à importância de ousar transformar práticas 
pedagógicas que vinham sendo adotadas sem que houvesse maior reflexão sobre sua pertinência e apontar a Pedagogia de Projetos como uma metodologia de ensino capaz de reverter problemas levantados no diagnóstico da rede. Destacam-se a seguir trechos de avaliações produzidas por educadores.

(...) em relação ao meu trabalho, acho que vou começar a pesquisar mais sobre minha clientela para conhecê-la melhor, e poder fazer um trabalho que sirva mais na vida deles e na minha. Professora E.E.M.T. (2004).

(...) a concepsão que eu tinha do que era montar, realizar e desenvolver um projeto mudou, já que boje tenho clareza de que projeto é algo vivo, que devemos problematizar algo a ser resolvido e solucionado (...) pretendo estar socializando o que aprendi com meu grupo de professores nos HTPCs. Coordenadora pedagógica P.V.S. (2005).

(...) consegui parar e observar ao meu redor, não me preocupando só com os conteúdos mas com o que tem valor para os meus alunos. Educadora não identificada (2005).

O curso Educação Ambiental e Interdisciplinaridade foi pensado a partir da constatação da dificuldade dos próprios coordenadores em romper com o olhar disciplinar. A fragmentação dos conteúdos em disciplinas estanques, que pouco ou nada dialogam, não tem razão de ser, especialmente nos anos iniciais do ensino fundamental, quando um mesmo professor transita por todas as áreas de conhecimento. Qual o sentido de separar ciências de língua portuguesa? Como trabalhar história sem tratar do território onde ela ocorre, com seu espaço geográfico e sua biodiversidade? A constatação da dificuldade de compreensão do ambiente como um todo integrado e interdependente motivou a construção de estratégias que pudessem facilitar a transformação do olhar sobre o conhecimento. Nos dois formatos do curso, oferecidos em 2007 e 2008, a transformação do ambiente com o decorrer da história foi o eixo norteador do conteúdo, que buscou inter-relacionar o caminhar da história com a alteração da 
paisagem e dos ecossistemas, apontando a interface da história da humanidade com a história da Terra. Os depoimentos de uma professora destacados a seguir registram a expectativa e a avaliação produzidas, antes e depois da realização do curso.

Minhas aulas já estão direcionadas, começando a trilhar o caminho da interdisciplinaridade, porém ainda sinto-me insegura às vezes e, por esse motivo, decidi aperfeiçoar-me neste sentido, pois acredito nesta proposta. Professora S.C. (08/05/2008).

Foi dez. Adorei! Esclareceu muitos pontos que ainda estavam obscuros na questão da interdisciplinaridade. Agora já estou mais tranqüila para realizar men trabalbo em sala de aula. Professora S.C. (20/05/2008).

Outro depoimento produzido na avaliação do curso merece atenção:

(...) Quero falar a verdade: quando eu estudava no ginásio era tudo escrito e eu não aprendia nada e não guardava nada na cabeça. Com aquela apresentação que a Sheila fez, no curso, eu aprendi muito porque ela fez diferente e mostrou a maquete explicando tudo. Foi uma "super"aula (...). Professora M.M.P. (2008).

A professora M.M.P. referiu-se a um módulo do curso no qual as alterações da paisagem do município ao longo da história foram demonstradas através de uma maquete de madeira, cujas "peças" foram movimentadas conforme a história foi sendo contada. O cenário de árvores frondosas e rios piscosos apresentado inicialmente transformou-se no contexto urbano vivido na atualidade. Esse depoimento traduz a experiência de uma professora que enquanto estudante viveu o que Paulo Freire (2000) chama de educação bancária e que em sua vida profissional despertou para uma nova forma de ensinar. 
As coordenadoras pedagógicas participaram de reuniões periódicas com a coordenação do Programa, nas quais foram realizados estudos, avaliações do processo e foram replanejadas ações. Nas reuniões, foram apresentados vídeos, realizadas dinâmicas e estudados diversos textos que posteriormente foram trabalhados pelos coordenadores junto às suas equipes de professores nos HTPCs. Como exemplo de vídeos que produziram reflexões bastante produtivas, podemos citar os da série "Aula lá fora”, produzida pelo MEC e na qual o ambiente no entorno da escola é utilizado como fonte de estudo. Como dinâmica, destacamos a produção de teatro com sucata partindo de textos de autoria de grupos de coordenadores, que discutiam problemas ambientais e suas possíveis soluções. Diferentes conteúdos foram trabalhados de forma dinâmica, sem maior ênfase no produto "teatro", mas no processo de elaboração e em todo o conhecimento mobilizado. Muitos textos contribuíram para a formação de coordenadores e foram levados por estes aos professores. Entre outros, foram estudados os PCN relacionados a Meio Ambiente e Objetivos e Metas do Ensino Fundamental, o Tratado de Educação Ambiental para Sociedades Sustentáveis e Responsabilidade Global, Carta da Terra, Agenda 21, Matrizes Curriculares de Referência do Sistema de Avaliação do Ensino Básico - Saeb, e diversos autores, entre eles Paulo Freire, Fernando Hernandez, Leonardo Boff, Moacir Gadotti, Isabel de Carvalho, Carlos Rodrigues Brandão, Mauro Guimarães e Marcos Reigota.

Está transcrito a seguir um trecho do Livro-Ata de HTPCs de uma das escolas envolvidas, registrando a atuação da coordenadora junto à sua equipe de professores a partir de atividades realizadas nas reuniões de formação de coordenadores, promovidas mensalmente pelo Programa Fruto da Terra. A atividade registrada a seguir foi desenvolvida com a formação de cinco grupos de professoras. Cada grupo recebeu e estudou o texto de um autor, refletiu sobre ele tendo como foco a relação entre o texto e o programa de educação ambiental em desenvolvimento na escola e posteriormente compartilhou suas conclusões com o restante do grupo. Os textos escolhidos proporcionaram maior reflexão sobre contextualização e não 
disciplinarização dos conteúdos escolares e sobre a educação como formadora de participação social.

(...) Foi realizado um trabalho em grupo [partindo das questões]: Como o fragmento de texto se relaciona com o fazer da nossa escola? Como acontece? Como poderia ser ou melhorar? Os textos trabalhados pelos grupos de professoras foram [extraídos dos livros]: Minha Casa o mundo, de Carlos Rodrigues Brandão; Os sete saberes necessários para a educação do futuro, de Edgar Morin; Educação Ambiental: Pesquisa e Desafios, de Michele Sato e Isabel Carvalho; Didática e Interdisciplinaridade, de Ivani Fazenda e [do artigo] Ler e Reler o mundo: construir um outro mundo possivel, de Angela Antunes. Após o trabalho realizado cada um apresenton suas reflexões sobre o texto lido. (HTPC realizado dia 18/11/2008, na EMEF Pref. Gilberto Santana).

Nos seis anos estudados, foi proporcionada aos profissionais das escolas a oportunidade de compreenderem melhor o ambiente local, através de vivência em importante remanescente de Mata Atlântica municipal, visita à Usina de Triagem e vivência em uma Área de Proteção Ambiental (APA) do município.

Textos sobre a importância da prática do registro foram estudados pelos coordenadores e pelas equipes escolares em HTPCs, fazendo com que olhares e práticas de muitos educadores mudassem em relação à produção de registros reflexivos. O que antes era visto como algo mecânico, como um "prestar contas", foi passando, pouco a pouco, a ser visto como a construção da história de profissionais e instituições.

Está transcrito a seguir o registro produzido por uma educadora após a realização de atividade de formação do Programa Fruto da Terra em um Parque Ecológico Municipal.

Tendo eu nascido e vivido aqui nesta terra, não havia nunca tido a oportunidade de conhecer a Grota Funda. (...) Quanto tempo perdido! Como pode algo de beleza tão rara estar aqui quase no anonimato, sem que quase ninguém tome consciência de sua existência e não tenha essa oportunidade de aprender com a natureza o que é viver em equilíbrio tão harmonioso mesmo sendo babitado por 
espécies tão diferentes. (...) a natureza nos dá alimento para o corpo e também para a alma (...) o cheiro de terra molhada, (...) o som da água cristalina que corre como uma veia na mata; (...) o que lá aprendemos (...) servirá para plantar no coração dos alunos uma semente (...) o quanto é importante cada ser que habita esta natureza, que tudo o que existe tem o direito de ser e o direito de viver (...)

Professora E.C.G.S. (2003).

Acreditamos que o registro escrito amplia a memória e historifica o processo, em seus momentos e movimentos, na conquista do produto do grupo. A escrita materializa, dá concretude ao pensamento, dando condições assim de voltar ao passado, enquanto se está construindo o presente. Mediados por nossos registros, armazenamos informações da realidade, do objeto em estudo, para poder refletir sobre ele, pensá-lo e assim apreendê-lo, transformá-lo, construindo o conhecimento antes ignorado (WEFFORT, 1996).

Como possibilidade concreta de o professor articular reflexão sistematizada e prática docente, o Programa Fruto da Terra trabalhou a produção de registros e apresentações de práticas educativas de sucesso, realizadas por seus professores-autores, nos Encontros Anuais de Educação Ambiental.

Foram realizados oito Encontros de Educação Ambiental do Programa Fruto da Terra nos seis anos analisados, sempre no início dos semestres, com suspensão de aulas para que todos os educadores pudessem participar em horário remunerado. Avaliações coletivas produzidas pelos educadores de forma voluntária, e sem obrigatoriedade de identificação, nortearam o replanejamento do formato desses encontros, que inicialmente ofereceram exclusivamente palestras, depois, palestras e oficinas, no ano seguinte, palestras e relatos de experiências, e então, exclusivamente relatos de experiências, formato com maior aprovação pelos educadores, conforme depoimento registrado a seguir.

Pude conhecer bons trabalhos realizados na rede e que dão novas idéias para nossos futuros projetos. (...) Confirmou como é importante olhar atentamente para 
a realidade, para a curiosidade das crianças e para a relação com o mundo. Professora A.B. (2007).

Esta troca é muito valiosa. Saio daqui querendo fazer, fazer, fazer. Aprendi que através de pequenas coisas podemos realizar outras com resultados grandiosos, para o mundo, não apenas para a sua classe de alunos. Professora S.C. (2007).

Projetos de educação ambiental desenvolvidos em um ano, quando bem registrados e bem avaliados por seus "professoresautores", foram apresentados a toda a rede pública municipal no início do ano seguinte tendo como objetivo motivar os demais educadores a ousar construir práticas pedagógicas inovadoras.

Aos poucos, mais educadores se propuseram a compartilhar com os colegas o processo educativo que desenvolveram e os resultados que conquistaram. Passaram a compreender essa atitude como uma importante contribuição para a melhoria da qualidade da educação do município.

Com a apresentação de experiências de sua autoria nos Encontros de Educação Ambiental, professores passaram a reconhecerse como produtores e disseminadores de conhecimento. Até 2008, 46 professores apresentaram seus projetos nos Encontros do Programa e foram realizados e apresentados projetos relacionados aos mais diferentes temas, entre eles: arborização urbana (Projeto Verde por todo lado), relações humanas (Projeto Paz), responsabilidade ambiental (Projeto Guardiões da natureza), consciência em relação às queimadas (Projeto Onde há fumaça há fogo), alimentação saudável e melhor aproveitamento dos alimentos (Projeto Batata Fujona), respeito à fauna (Projeto Um ninho em nossa árvore), respeito à vida humana (Projeto Convivendo bem com as diferenças), entre outros. Temas relacionados a relações humanas aos poucos foram sendo incorporados ao processo, como os projetos "Vamos acabar com o preconceito: queremos um mundo melhor" ou "Sim à honestidade e não à violência", realizados em 2007 e 2008, respectivamente. 
A socialização de práticas de educação ambiental de sucesso aconteceu também através de edições periódicas do Jornal Fruto da Terra, que soma 15 edições, com 14.000 exemplares cada uma. Elaborado exclusivamente com produções de alunos e relatos de educadores, o jornal foi distribuído a todos os alunos e profissionais da rede pública municipal.

Acreditando na importância do processo de socialização de experiências, foi idealizada também a Exposição Municipal de Educação Ambiental do Programa Fruto da Terra, que aconteceu nos meses de novembro de cada ano, desde 2003. Todas as escolas receberam um ou dois estandes onde apresentaram projetos de educação ambiental realizados naquele ano letivo. Era apresentada a justificativa para a escolha do tema, eram compartilhados registros das estratégias desenvolvidas e apontados os resultados conquistados. Apresentações de palco com dramatizações, corais e danças foram realizadas por alunos e alunas durante todo o dia, em todos os anos. As exposições foram momentos de troca de experiências entre equipes de diferentes escolas e também de sensibilização dos familiares das crianças quanto à importância da educação ambiental.

A sistematização do Programa Fruto da Terra consolidou o processo de produção e disseminação de práticas educativas de educação ambiental, conforme descrito a seguir.

Tabela 1 - Sistematização do Programa de Educação Ambiental Fruto da Terra: periodicidade das atividades desenvolvidas anualmente

\begin{tabular}{|l|c|c|c|c|c|}
\hline & $\begin{array}{c}\text { Reuniões c/ } \\
\text { coordenadoras }\end{array}$ & $\begin{array}{c}\text { Cursos de } \\
\text { educação } \\
\text { ambiental }\end{array}$ & $\begin{array}{c}\text { Encontro de } \\
\text { Formação }\end{array}$ & $\begin{array}{c}\text { Jornais } \\
\text { Fruto da } \\
\text { Terra }\end{array}$ & $\begin{array}{c}\text { Exposição } \\
\text { municipal de } \\
\text { EA }\end{array}$ \\
\hline fevereiro & $\mathrm{X}$ & & & & \\
\hline março & $\mathrm{X}$ & $\mathrm{X}$ & & & \\
\hline abril & $\mathrm{X}$ & $\mathrm{X}$ & $\mathrm{X}$ & & \\
\hline maio & $\mathrm{X}$ & & & $\mathrm{X}$ & \\
\hline junho & $\mathrm{X}$ & & & & \\
\hline agosto & $\mathrm{X}$ & $\mathrm{X}$ & & $\mathrm{X}$ & \\
\hline setembro & $\mathrm{X}$ & & & & \\
\hline outubro & $\mathrm{X}$ & & & & $\mathrm{X}$ \\
\hline novembro & $\mathrm{X}$ & & & & $\mathrm{X}$ \\
\hline
\end{tabular}




\section{Metodologia do ensino}

A importância de uma educação contextualizada é consenso nos discursos, mas ainda não é realidade nas escolas. É sim preciso situar informações e dados em seu contexto para que adquiram sentido, mas é preciso ir além. O desafio da educação ambiental vai além da associação de dados com a realidade vivida. É preciso englobar emoções e conhecimentos, valores e comportamentos, de forma sistêmica, circular, na qual emoções, conhecimentos, valores e comportamentos reforcemse uns aos outros. Desse ponto de vista da educação ambiental, o meio ambiente já não é necessariamente o natural, preservado, por conservar, tampouco aquele tão distante que o indivíduo não possa intervir. $\mathrm{O}$ meio ambiente é o ambiente próximo, cotidiano, aquele em que pequenas iniciativas podem começar a modificar atitudes, modos de atuar e formas de compreender o mundo (MAYER, 1998, apud EDWARDS et al., 2004).

Ab'Saber afirma que a educação ambiental é uma ação, talvez utópica, destinada a reformular comportamentos humanos e recriar valores perdidos ou jamais alcançados. Para o autor, é um processo de educação que garante um compromisso com o futuro, envolvendo uma nova filosofia de vida e um novo ideário comportamental, tanto em âmbito individual quanto em escala coletiva (AB'SABER, 1994, apud SATO; CARVALHO, 2005). Não é possível "recuperar valores" sem compreender o mundo mais próximo. Quando o conteúdo estudado em sala de aula promove uma maior compreensão do contexto vivido pelas crianças - do ambiente dentro e fora da escola, do bairro, cidade, região -, o conhecimento adquire sentido, ganha vida, transforma o modo como as crianças percebem e se relacionam com o mundo. Passa então a existir maior possibilidade de reformular comportamentos e recriar valores.

Acreditamos, assim, que a educação ambiental implica mudanças nos conteúdos educacionais que vão além de uma melhor integração das diversas disciplinas contidas nos programas curriculares tradicionais. A educação ambiental exige a criação de um saber ambiental e sua assimilação transformadora às disciplinas deve gerar os conteúdos concretos de novas temáticas ambientais (LEFF, 2001). 
A educação ambiental a partir da Pedagogia de Projetos foi a opção escolhida pelo programa para promover ambientes educativos de mobilização de processos de intervenção sobre a realidade e seus problemas socioambientais, aliando a educação ambiental efetivamente à transformação de valores e atitudes, ao exercício de cidadania.

O conhecimento proporcionado pela escola passou então, em certa medida, a incluir a análise crítica das informações ou situações e a possibilidade de intervenção na realidade. Aliar o comprometimento dos profissionais da educação à transformação de práticas diárias em relação ao ambiente e ampliar o olhar do grupo quanto ao universo de conhecimento à disposição da escola foram objetivos constantemente perseguidos pelo programa. Através da metodologia adotada, a relação dos alunos com o meio onde estão inseridos passou a nortear a organização curricular de um número crescente de educadores.

O relato a seguir, transcrito de um Livro-Ata de HTPCs, ilustra essa afirmação:

(..) as professoras comentaram então as respostas da pergunta que foi lançada no semanário: $O$ que são atividades contextualizadas? Sempre penso nas atividades que irei elaborar para meus alunos, me preocupo se as mesmas são significativas, se irão ajudá-los a evoluirem e sempre procuro contextualizá-las. - Prof. K. Acredito que elas têm mais significado, pois o assunto de interesse da criança é visto em todas as disciplinas, sem cortes, já que há ligação muitas vezes ou todas as vezes entre as disciplinas. As atividades realizadas de acordo com o interesse dos alunos são uma forma de colocar a sala "preocupada" em aprender, sem distração, monotonia e aprender com desejo. - Prof. S. A atividade contextualizada leva o aluno a um verdadeiro conhecimento e não à simples informação. Deve estar bem próxima a fatos ou situações da vida dos alunos, assim eles participam ativamente da construção do conbecimento. - Prof. M. Após a discussão assistimos ao vídeo da TV-Escola: Trabalhando com Projetos. (...) (HTPC realizado dia 05/10/2006, na EMEF Pref. Gilberto Santana).

A prática pedagógica organizada através de projetos pode dar maior sentido ao conhecimento e favorecer a construção de estratégias para abordar e pesquisar problemas que vão além da compartimentação 
disciplinar. A disposição do grupo em compreender melhor determinado aspecto de sua realidade provocou o diálogo com profissionais de diferentes áreas, caminhadas pelo bairro, aulas-passeio para estudo do ambiente e entrevistas. Assim, o universo de conhecimento se ampliou, fazendo com que o livro didático fosse um dos importantes instrumentos de busca de informações, mas não o único.

O estudo sobre a importância do registro refletiu-se também na forma como as crianças passaram a relatar as atividades de que participaram. Estão transcritos a seguir registros de dois alunos após uma aula-passeio no Parque Ecológico Municipal.

Dia 3 de agosto minha classe foi à Grota Funda, lá é uma grande floresta. (...) $V$ imos o Jequitibá, é uma árvore bem grande, a maior da floresta. Fomos até um riacho, até uma nascente, a água é natural, fresquinha e boa (...). Aluna G. (2005).

(...) Nós entramos na trilha. Tinha que passar por troncos caídos, desviar de árvores, subir em pedras e também vimos um Jequitibá e a árvore de canela. (...). Aluno L.A. (2005).

É fundamental que uma educação ambiental que se pretende crítica e transformadora procure reduzir a distância existente entre o que é ensinado nas escolas e a cultura da comunidade em que está inserida, ou seja, o conjunto de valores, crenças e significações que os alunos utilizam para dar sentido ao mundo em que vivem (HERNÁNDEZ, 1998). Quando a aprendizagem faz sentido, quando o aluno desenvolve um olhar atento e curioso em relação aos fenômenos e acontecimentos à sua volta, busca compreendê-los utilizando-se de diferentes fontes e percebe a relação existente entre o conteúdo estudado e suas atitudes; então, a escola está contribuindo para formar a autonomia e o senso crítico, indispensáveis para o pleno exercício da cidadania. Um conhecimento escolar centrado em livros, distante do ambiente vivido pelas crianças, não contribui para o comprometimento do grupo com a comunidade, não transforma atitudes nem fortalece valores. 
A opção pela Pedagogia de Projetos alia a compreensão do meio com a intervenção na realidade e organiza o fazer pedagógico partindo da realidade concreta da vida cotidiana dos próprios participantes, em suas diferentes dimensões e interações.

A liberdade na construção de práticas de educação ambiental partindo do olhar atento do educador aos seus alunos, sua história e cultura, em um primeiro momento, causou insegurança. Insegurança em abandonar a sequência de temas proposta pelos livros didáticos e participar da construção de um novo caminho de ensino-aprendizagem, que buscasse relacionar o ambiente - físico e social - dentro e fora dos muros da escola, com a escolha de temas e problemas a serem estudados e/ou solucionados. O curso de pedagogia de projetos oferecido aos profissionais da rede municipal deu pistas, mas não receitas. Era preciso que educadores e educandos partilhassem interesses, dúvidas e soluções, definissem e construíssem conteúdos e caminhos, reaprendessem a aprender.

Estudos realizados em HTPCs, conforme o trecho transcrito a seguir, alimentaram o processo de formação dos educadores ao longo do período estudado:

(...) após a leitura do texto fizemos a reflexão: o letramento já acontece, na roda de conversa informal, conbecendo a história do aluno, do bairro onde estão inseridos, valorizando a cultura diversificada que encontramos em sala de aula, pois cada um tem uma maneira de se expressar no mundo. A partir dai, monta-se um curriculo vivo, que vá ao encontro dos interesses, do que querem aprender, os conteúdos inseridos dentro dos projetos desenvolvidos em classe, onde a interdisciplinaridade contempla as áreas do conhecimento abordando a realidade e conteúdos significativos. Realizamos a leitura final de todas as reflexões levantadas durante o estudo do documento, reflexões sobre o perfil dos nossos alunos, a proposta pedagógica, os projetos desenvolvidos (...) (HTPC realizado dia 08/06/2007, na EMEF Pref. Gilberto Santana).

As transformações observadas nos projetos elaborados pelos educadores indicam resultados conquistados ao longo da história do programa. A dissociação entre os conteúdos estudados e a realidade 
vivida pelas crianças passou a dar lugar a práticas pedagógicas mais contextualizadas, em maior sintonia com o que é preconizado pelos PCN: "desenvolver uma prática pedagógica que leve o aluno a perceber-se integrante, dependente e agente transformador do ambiente", "leve-o a questionar a realidade formulando-se problemas e tratando de resolvê-los".

Aos poucos, o espaço de aprendizagem se ampliou. No projeto Verde por todo lado, por exemplo, desenvolvido em 2005, as ruas no entorno da escola passaram a ser estudadas pelas crianças de uma terceira série, que saíram para observar três ruas com um "Roteiro para Observação no Bairro” em mãos. A partir da atividade e das reflexões que surgiram, mudas de espécies adequadas à arborização urbana foram levadas para a escola, cuidadas e estudadas pelas crianças, que ao final do ano buscaram moradores do bairro que as pudessem "adotar". Destacam-se os depoimentos de alguns alunos, registrados a seguir.

Quando a gente não estudava este projeto Verde Por todo Lado, eu só sabia que as árvores purificam o ar e diminuem o calor. Agora eu sei muitas coisas. E nesse Projeto plantei a minha primeira muda da minha vida. Essa experiência en nunca vou esquecer. Aluno L. (2005).

(...) aprendi que o buraco que fazemos para colocar as mudas se chama berço, $e$ não cova, porque cova é onde se coloca coisa morta e árvore é um ser vivo. Aluna T. (2005).

(...) aprendi que o pássaro come a semente de árvore, e a semente sai pelas fezes do pássaro e vai depois nascer uma linda árvore. Aluna A. (2005).

No mesmo ano, foi realizado o projeto Onde há fumaça há fogo, cujo tema foi escolhido porque a escola vinha sendo invadida por fumaça provocada pelas queimadas realizadas no bairro. O que era visto exclusivamente como transtorno ao bom andamento das aulas tornou-se motivo de estudo, curiosidade e importantes descobertas para crianças de uma terceira série. O grupo realizou excursões pelo bairro para observar o solo sob a mata e o solo após a realização de queimadas, realizou 
diferentes experiências que possibilitaram compreender de que forma o fogo interfere na atmosfera, entrevistou bombeiros, confeccionou desenhos e mapas e passou a produzir composto orgânico na escola. Nesse projeto, o objeto de estudo se ampliou ainda mais, deixando de ser apenas o ambiente vizinho à escola. O projeto transformou a organização curricular e a escolha dos conteúdos a serem estudados partiu da observação da realidade, que passou a motivar o interesse e a curiosidade dos alunos em estudar ciências e geografia e produzir textos, desenhos e mapas. Foram registrados pela professora e transcritos abaixo alguns depoimentos produzidos antes e depois da realização do projeto, demonstrando transformações na percepção das crianças em relação à prática de queimadas.

Depoimentos produzidos no primeiro semestre de 2005, antes da realização do projeto Onde há fumaça há fogo:

O fogo quando queima o terreno não precisa carpir. É melhor do que carpir. Aluno J. -9 anos.

O fogo serve quando o caminhão do lixo não passa e a gente joga o lixo no quintal e bota fogo. Aluno R.O. - 10 anos.

Eu acho bom queimadas porque não acumula lixo. Aluna P. - 9 anos.

É divertido p[ô] r fogo no mato. Aluno R.L. - 10 anos.

Depoimentos produzidos no segundo semestre de 2005, após a conclusão do projeto:

A gente não pode brincar de fazer queimada. Ela não é boa para ninguém. Ela pode matar tudo de bom da natureza. Aluna M. - 10 anos.

Antes eu pensava que a queimada não era nada. Mas hoje eu sei que prejudica a gente e vários animais. Aluna D. - 10 anos. 
Aprendi que a queimada não queima só as árvores, mas também os bichinhos que estão debaixo da terra. Aprendi que não produz nenhum alimento se tiver muita queimada. Aluno L. - 10 anos.

... ela queima o oxigênio e deixa bem pouquinho. E só faz aumentar o gás carbônico que provoca tosse e bronquite nas crianças. Aluno R.O. - 10 anos.

Outra atividade do programa foi o curso Educação Ambiental e Interdisciplinaridade, oferecido em 2007 e 2008, que contribuiu para a percepção de uma unidade no conhecimento humano, para a percepção da existência de uma única história, planetária. Segundo Charlot (2005), não se pode pensar a natureza nem o ser humano sem pensar a ação humana sobre a natureza. Há uma identidade entre ambos (CHARLOT, 2005, apud SATO; CARVALHO, 2005).

Como instrumento facilitador da organização curricular não disciplinar, foi proposta a utilização das Matrizes Referenciais Curriculares do Saeb, publicadas pelo MEC. Uma vez elaborados os Projetos de Educação Ambiental, os educadores foram incentivados a buscar nos Descritores do Saeb o conteúdo considerado possível de ser abordado, de forma contextualizada e significativa, a partir do tema estudado. Os conteúdos eram então elencados e passavam a nortear a abordagem seguida pelo educador, que escolhia a sequência que melhor atendia às necessidades ou ao interesse do grupo, transitando por todas as áreas do conhecimento.

Está transcrito a seguir mais um trecho do Livro-Ata de HTPCs de uma das escolas envolvidas:

(...) continuamos com o assunto A bistória do povo brasileiro. Realizamos uma discussão bastante interessante, revimos os conceitos históricos que eram passados para nós antigamente, textos e questionários, sem uma reflexão, apenas decorebas, memorização. Trabalhamos com as matrizes curriculares [do Saeb] de História, Geografia e Ciências e percebemos que é um material rico, e que nos orienta para trabalharmos temas transversais entre as disciplinas. Através das imagens que foram apresentadas no computador [material produzido pela coordenação do Programa Fruto da terra, trabalhado com as coordenadoras e 
disponibilizado para as escolas] as professoras realizaram uma atividade, onde escreveram o que podiam trabalhar com os alunos relacionando com as imagens referentes à pré-história, Brasil indígena, Brasil Colônia e Brasil Contemporâneo. (...) (HTPC realizado dia 16/05/2006, na EMEF Pref. Gilberto Santana).

Em 2007, observamos a ampliação do horizonte estudado. No Projeto Guardiões da Natureza, desenvolvido junto a uma $2^{\mathrm{a}}$ série, o professor iniciou abordando a relação ser humano-natureza ao longo da história do Brasil, ainda que de forma superficial devido à faixa etária das crianças. Na sequência, foram realizadas atividades de observação e interferência no espaço interno da escola, observação e estudo do bairro onde a escola está inserida e aula ao ar livre em trilha na Serra do Itapetinga.

Estão transcritos a seguir trechos de depoimentos das crianças após a aula-passeio para observação do bairro.

Um dia saímos da escola com a tia Joyce e o professor Sérgio. Nós saimos pelas ruas vendo a natureza como está poluida! Nós andamos e vimos várias árvores com galhos secos e tiramos fotos das árvores. Eu vi o esgoto a céu aberto. Eu e a Kathellen ficamos muito tristes. Alunas O. e K. (2007).

Nós tiramos muitas fotos. Tiramos fotos de plantas bonitas depois tiramos uma foto de um córrego, lá tinha uma cadeira, lá tinha muito lixo. Aluno A.F. (2007).

As crianças foram levadas então a refletir sobre a pergunta: "O que podemos fazer para mudar a realidade?”. Uma aluna trouxe de casa uma receita de produção de sabão a partir de óleo de cozinha usado, pois havia ficado impressionada com o óleo encontrado no córrego do bairro. A classe decidiu sensibilizar a comunidade escolar em relação aos problemas ambientais observados, utilizando para isso a rádio escolar e a confecção de cartazes. Algumas das frases produzidas para sensibilizar os colegas estão registradas a seguir.

Não corte árvores você está desrespeitando a lei. Aluno V. (2007). 
Parabéns você está ajudando a reciclar. Aluno I. (2007).

É bom lavar a bicicleta com o balde, pois lavar com a mangueira gasta mais água. Aluno L. (2007).

O professor desenvolveu uma prática pedagógica que levou os alunos a perceberem-se integrantes e agentes transformadores do ambiente. As estratégias escolhidas levaram as crianças a questionar a realidade pensando soluções para os problemas percebidos. Passaram a agir de acordo com o preconizado por Freire quando este afirma que o conhecimento deve proporcionar a capacidade de intervir na realidade, levar à busca por mudança, soluções, e não à adaptação (FREIRE, 1996).

\section{Contribuições e limitações do método adotado, tendo como foco a educação ambiental crítica}

É possível afirmar que houve um avanço na inserção do ambiente externo à escola no conteúdo estudado e passou a existir uma maior preocupação dos educadores com a contextualização dos temas escolhidos. Muitos acreditam na Pedagogia de Projetos como um importante instrumento de educação ambiental, sentem-se ano a ano mais seguros para desenvolvê-la e relatam inclusive a preferência das crianças por essa metodologia de ensino.

Antes do trabalho com projetos, os conteúdos de história, geografia e ciências eram definidos pelos livros didáticos. Com a prática da pedagogia de projetos, o conteúdo a ser trabalhado foi definido a partir do interesse ou da necessidade de grupos específicos de crianças, em determinado contexto, consideradas suas especificidades.

A transformação de atitudes e valores e a construção de soluções para os problemas percebidos passaram a ser, de alguma forma, observados nos projetos. O conhecimento pouco a pouco deixou de ser restrito aos livros, passando a ter aplicação na vida real, observando-se maior comprometimento dos educadores com o engajamento das crianças na transformação da realidade mais próxima. 
Um exemplo significativo é a atitude das crianças da EMEF Waldemar Bastos Buhler em relação ao terreno em frente à escola, antes cheio de mato e utilizado como depósito de lixo. Mediadas pela professora, as crianças produziram uma carta dirigida à Secretaria de Serviços pedindo que o terreno fosse limpo para que uma praça pudesse ser instalada no local. Produziram mudas na escola, realizaram mutirões de plantio, enviaram novas cartas solicitando auxílio, até que finalmente conseguiram ver seu sonho realizado. Mais do que geografia e língua portuguesa, com os mapas e cartas produzidos as crianças aprenderam a não desistir do que acreditam, aprenderam que são capazes de intervir na realidade.

Mas também é evidente que todos esses resultados não foram observados na maioria dos educadores, ainda que o programa tenha sido desenvolvido por seis anos. Trabalhar com projetos contribuiu para a realização da educação ambiental crítica nas escolas, mas não foi a solução para todos os problemas. Transformações duradouras nas práticas pedagógicas demandam transformação antes de tudo da forma de compreender o mundo do próprio educador, de sua postura política em relação à vida, da concepção da relação sociedade-natureza que este possui. Transformações efetivas na forma de ensinar exigem repensar a forma de perceber o mundo e de perceber-se no mundo. Além disso, trabalhar com projetos implica sair do ambiente "seguro" da sala de aula, possibilitado por métodos de ensino mais tradicionais; significa despir-se da certeza das respostas, não ser mais detentor do conhecimento, mas mediador de sua construção. Significa estar aberto ao imprevisto, estar disposto a redesenhar seu planejamento de acordo com a vivência proporcionada, romper hierarquias e conviver com o novo. Impõe estar em constante construção de estratégias de ensino dialogadas com os alunos. Essa necessidade constante de renovação é uma importante limitação do método. Não há "calmaria", ou, conforme Boutinet (2002), o horizonte do projeto remete sempre a seu próprio envelhecimento, ao esgotamento das energias que mobiliza.

Outra dificuldade enfrentada pelo método é a organização do currículo durante toda a vida escolar do aluno, de forma a não existir sobreposição nem exclusão de conteúdos importantes. Considerando que 
o que mobiliza a escolha de conteúdos é o tema, ou o problema eleito como prioritário de acordo com a realidade de cada grupo, é possível que alguns conteúdos importantes deixem de ser estudados. Aí está a importância de um bom registro feito pelo professor, no qual constem todos os tópicos abordados durante o ano letivo, e da análise desse registro pelo professor que assume a sala no ano seguinte. O Programa Fruto da Terra propôs essa prática tendo como instrumento-base os descritores curriculares do Sistema de Avaliação do Ensino Básico, os quais incluem conteúdos, competências e habilidades a serem desenvolvidas durante todo o primeiro ciclo do Ensino Fundamental. Esse documento pode ser uma referência de conhecimentos mínimos a serem garantidos às crianças durante a primeira fase de sua vida escolar. Trabalhar com projetos não significa a inexistência de preocupação em garantir conteúdos, mas abordá-los de forma significativa e contextualizada, identificando possibilidades de participação ativa das crianças na busca de soluções para eventuais problemas percebidos. Um bom exemplo é a produção de hortas escolares como estratégia para reeducação alimentar, melhor aproveitamento dos alimentos e destinação adequada de resíduos. Em alguns casos observados, nos quais foi inclusive produzido composto orgânico pelas crianças, o solo deixou de ser estudado. $O$ foco do projeto foi priorizado e a oportunidade de estudo das características do solo, dos seus componentes e da sua relação com a produção dos alimentos foi desconsiderada. A realização desse constante diálogo entre os projetos elaborados e a garantia do conhecimento a que as crianças têm direito e necessidade são questões não completamente resolvidas durante os seis anos estudados.

$\mathrm{O}$ estudo realizado indica, entretanto, que a prática da pedagogia de projetos contribuiu para o rompimento do imobilismo provocado pelo ensino centrado nas disciplinas e descontextualizado, além de ter fortalecido a relação das crianças entre si e com os ambientes onde vivem. A estratégia de ensino adotada tem limitações que necessitam ser superadas, mas o estudo dos seis anos de realização do Programa Fruto da Terra indicou um importante avanço para a efetivação da educação ambiental crítica na rede pública municipal analisada. 


\section{Referências}

ALVES-MAZZOTTT, Alda Judith. O método nas ciências naturais e sociais: pesquisa quantitativa e qualitativa. São Paulo: Pioneira, 2004.

BOUTINET, Jean-Pierre. Antropologia do Projeto. São Paulo: Artmed, 2002.

COMPIANI, Maurício. Geologia/Geociências no ensino fundamental e a formação de professores. Geologia USP - Publicação Especial, São Paulo, v. 3, p. 13-30, set. 2005.

EDWARDS, Mónica; GIL, Daniel; VILCHES, Amparo; PRAIA, João. La atención a la situación del mundo en la educación científica. Enseñanza de las Ciencias, Barcelona, v. 22, p. 47-63, mar. 2004.

FERRARO JÚNIOR, Luiz Antonio. Encontros e Caminhos: formação de educadoras(es) ambientais e coletivos educadores. Brasília: MMA, 2005.

FREIRE, Paulo. Pedagogia da Autonomia. São Paulo: Paz e Terra, 1996. . Pedagogia da Indignação. São Paulo: UNESP, 2000.

GUIMARÃES, Mauro. A formação de educadores ambientais. Campinas: Papirus, 2004.

HERNÁNDEZ, Fernando. Transgressão e Mudança na Educação. Porto Alegre: Artmed, 1998.

LEFF, Enrique. Saber Ambiental: sustentabilidade, racionalidade, complexidade, poder. Petrópolis: Vozes, 2001.

NEVES, José Luis. Pesquisa qualitativa: características, usos e possibilidades. Caderno de Pesquisas em Administração, São Paulo, v. 1, n. 3, p. 1-5, jul./dez. 1996.

SATO, Michèle; CARVALHO, Isabel Cristina de Moura. Educação Ambiental: Pesquisa e Desafios. Porto Alegre: Artmed, 2005.

WEFFORT, Madalena Freire. Observação, registro e reflexão. São Paulo: Espaço Pedagógico, 1996.

YIN, Robert K. Case Study Research: Design and methods. London: Sage Publications, 2003.

Artigo: recebido em 11/11/2008 - aprovado em 05/09/2009 